\title{
Sturgeon Research Update: Confirmed Pallid Sturgeon Spawning in the Missouri River in 2007
}

The U.S. Geological Survey (USGS) in partnership with the Nebraska Game and Parks Commission (NGPC) and the U.S. Army Corps of Engineers have confirmed spawning of two female pallid sturgeon in the upstream reaches of the lower Missouri River in May 2007. Combined with supporting research in reproductive physiology, identification of spawning habitat, and early life history this result provides new understanding of environmental factors (for example, photoperiod, temperature, water quality, and flow regime) that might affect reproduction of this endangered species. The purpose of this fact sheet is to provide

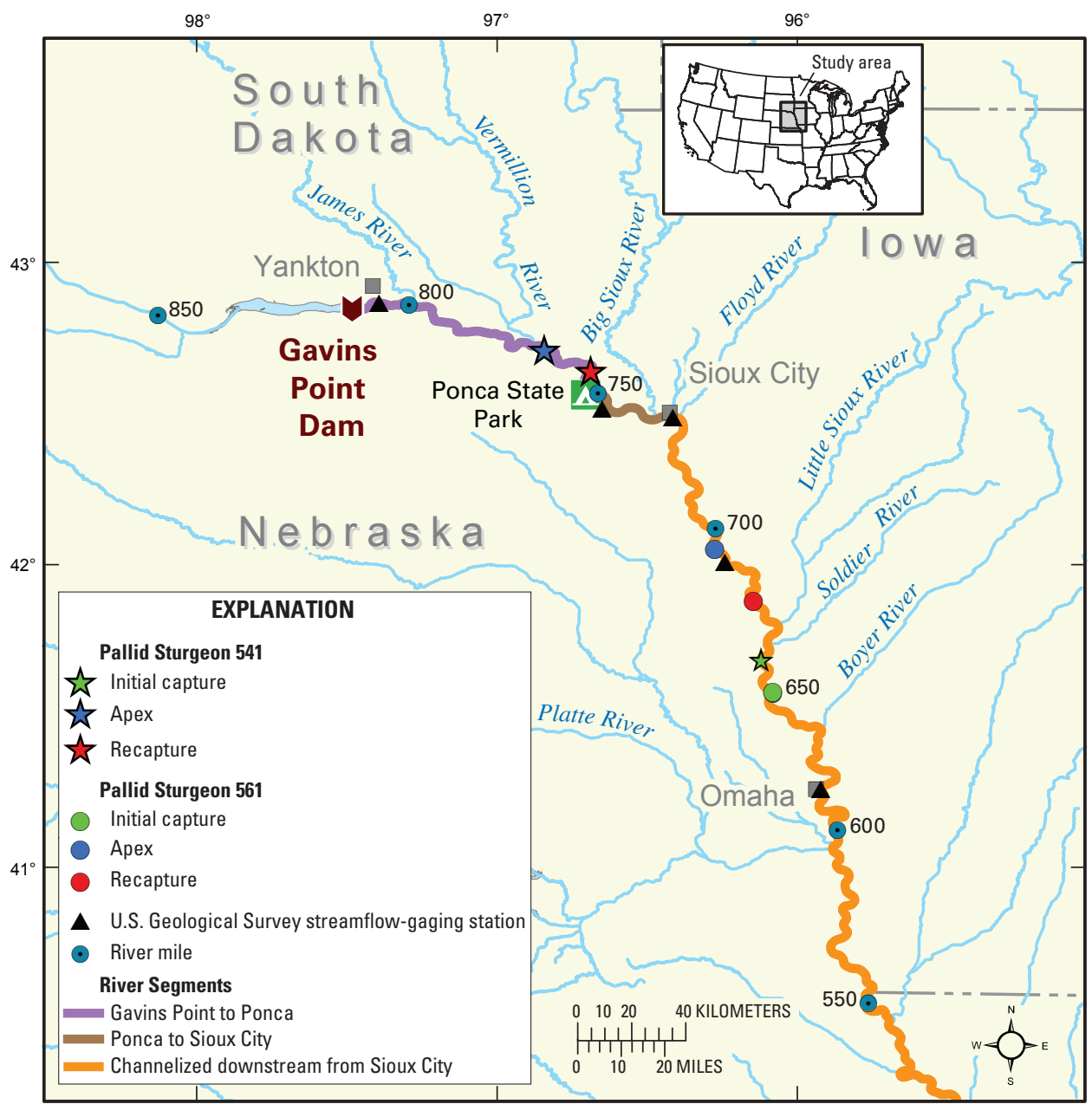

Figure 1. Study area for 2007 field assessment of sturgeon reproduction, Lower Missouri River.

stakeholders, scientists, and managers with some of the preliminary results from the 2007 field assessment of sturgeon reproduction in the lower Missouri River.

\section{Background on Sturgeon Research}

The USGS and NGPC are involved in a multi-year, collaborative research study to determine factors leading to spawning and survival of the endangered pallid sturgeon and the closely related shovelnose sturgeon. During spring 2007 researchers tracked the movements of 195 sturgeon between Omaha, Nebraska, and Gavins Point Dam, South Dakota (fig. 1). The purpose of the study is to determine $96^{\circ}$ 
pulses that are reflected in the USGS Sioux City streamflow-gaging station record (fig. 2).

The variable hydrology was distributed among three geomorphically distinct river segments (fig. 1). From Gavins Point Dam (river mile 811) to Ponca State Park (river mile 753.5), the river is characterized by complex

\section{Preliminary Results from 2007}

In March and April 2007, 8 pallid and 176 shovelnose sturgeon were surgically implanted with CART series transmitters that permitted researchers to track their movements in the river. The fish also were implanted with archival data storage tags (DST's) that record depth and
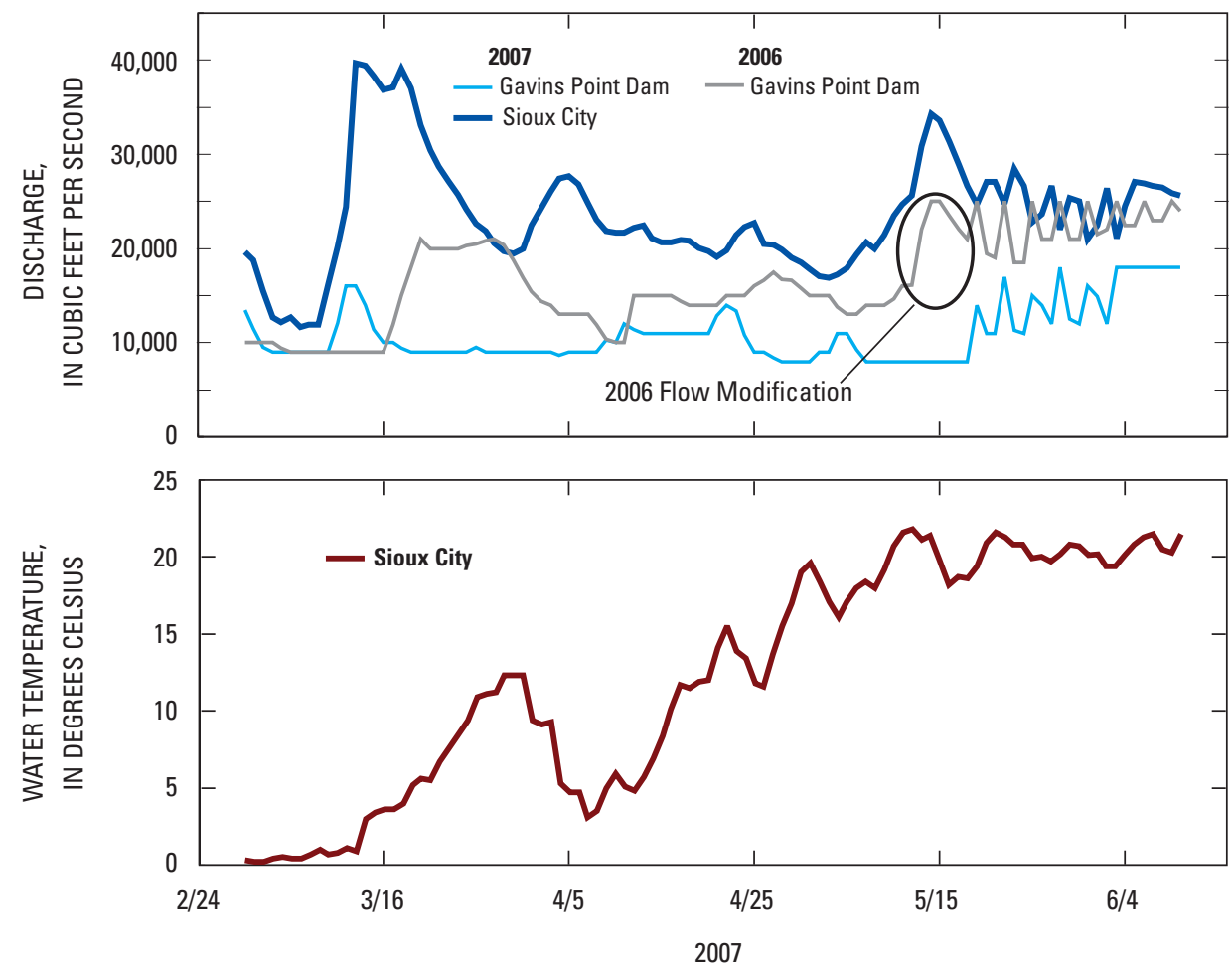

Figure 2. Hydrograph and water temperature showing variation of Missouri River environmental conditions during March through May 2007.

reaches with dynamic sandbars, multiple channels, and islands. From Ponca State Park to Sioux City, Iowa (river mile 734), the river channel is transitional to the engineered, navigation channel. This reach has been narrowed and stabilized with bank revetment and some wing dikes, but maintains some mid-channel sandbars and channel complexity. Downstream from Sioux City, the river has been channelized for navigation and is mostly a single-thread channel with rare mid-channel sand bars.

Variable hydrology and morphology of the mainstem Missouri River and tributaries resulted in a range of potential interactions between environmental cues and habitat availability for sturgeon during spring 2007. Although it will be challenging to isolate which factors had the greatest affect on sturgeon spawning, the large number of tagged fish in this field assessment will provide an extensive dataset for analysis.

temperature (fig. 3). The reproductive condition of each fish was determined through ultrasonic and endoscopic examination and by visual examination of the gonads during implantation. Of the pallid sturgeon implanted, two females and three males were in reproductive condition and expected to spawn during 2007. Another 11 pallid sturgeon that had been implanted previously with transmitters in 2006 also were tracked within and below this river reach. The reproductive readiness to spawn was assessed for each female pallid and shovelnose sturgeon at the time of implantation using the egg polarization index measurement, which is an indication of how soon a female will spawn; the egg polarization index decreases as the time of spawning draws near. A polarization index value of 0.07 or less indicates that spawning is imminent. Additional shovelnose sturgeon were captured weekly throughout the spring to monitor when the sturgeon population within these river segments would be physiologically capable of spawning.

Intensive tracking efforts were initiated in April on the two female pallid sturgeon in reproductive condition. In early May, based on water temperature and behavioral movements, 24 hour continuous tracking efforts were initiated. Two boats operated by NGPC conducted

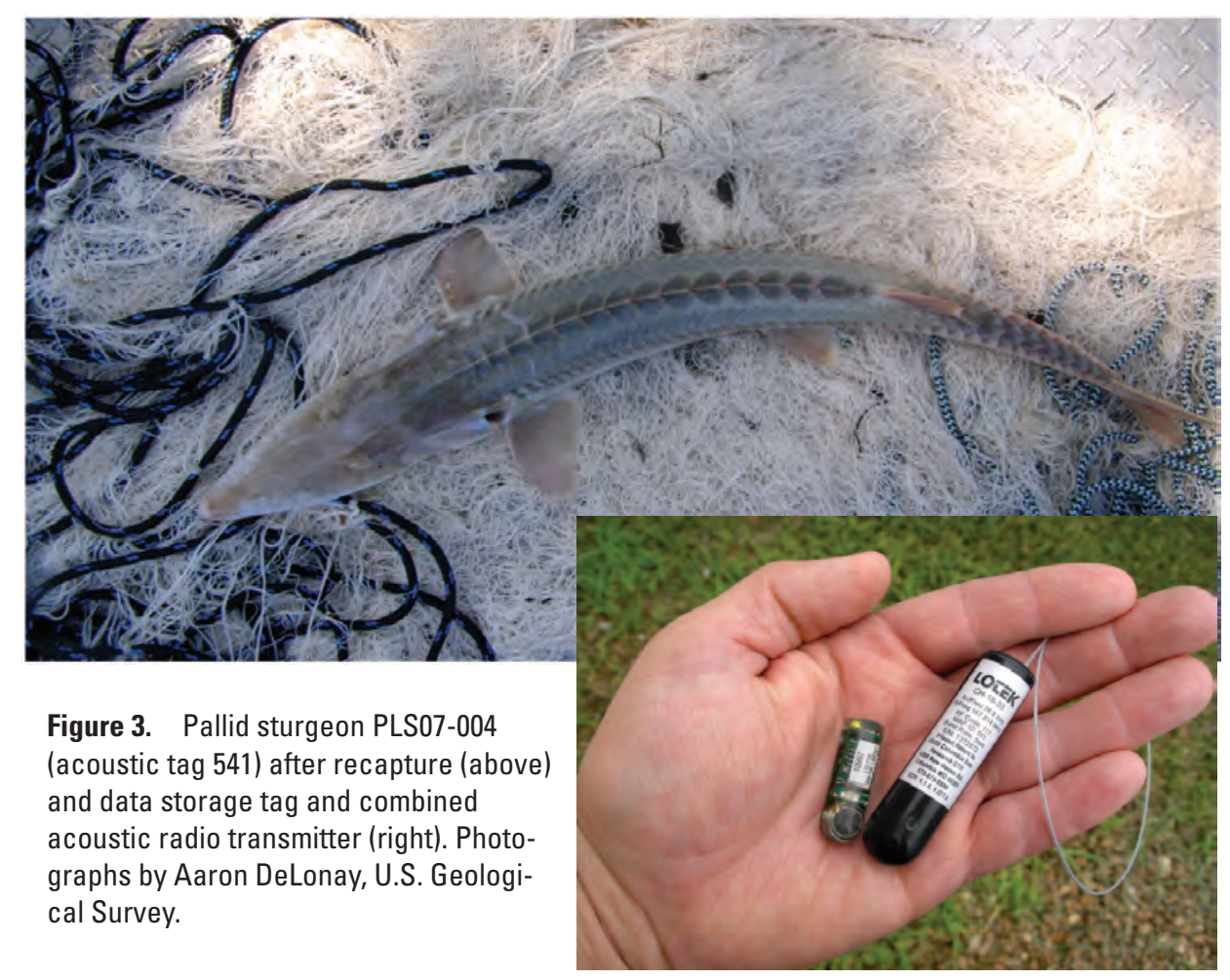




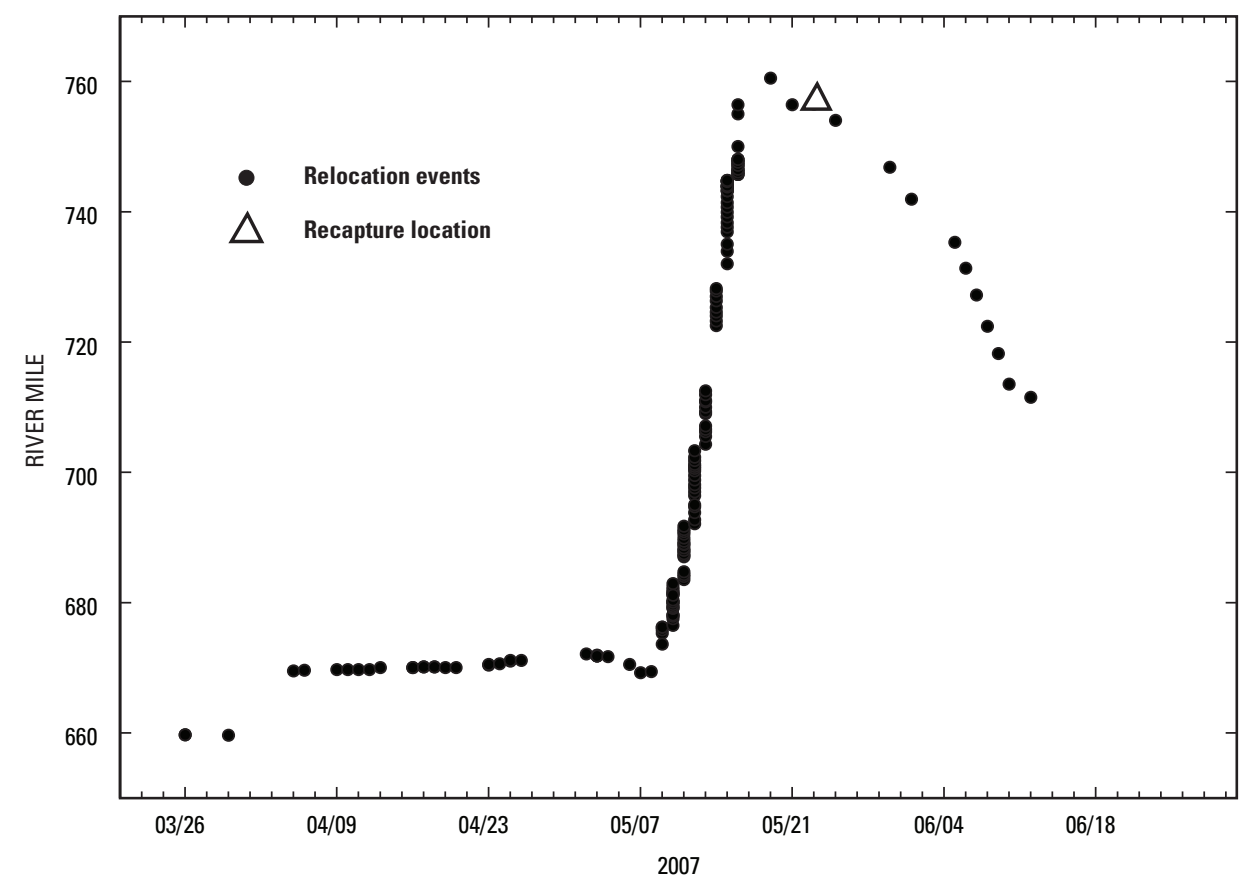

Figure 4. Relocation events for female pallid sturgeon PLS07-004 (acoustic tag 541, fig. 3).

the intensive tracking efforts. The USGS conducted extensive river tracking efforts for all tagged sturgeon and served as reserve vessels for the intensive pallid sturgeon tracking efforts. Field crews from the NGPC and USGS relocated each reproductive female pallid sturgeon more than 100 times in a 2-month interval before attempting to recapture them to determine if they had spawned (fig. 4).

Both female pallid sturgeon showed intervals of rapid upstream movement, followed by intervals of slower downstream movement with extended pauses. This characteristic movement pattern was noted by the USGS in an earlier phase of this study in 2005 and 2006. The earlier study focused on spawning individuals of the closely related shovelnose sturgeon. We infer that spawning generally occurs at the upstream apex of these movements. The USGS and NGPC recovered the two telemetry-tagged pallid sturgeon females from the Missouri River. USGS researchers re-examined each female with ultrasound and an endoscope in the field to determine if spawning occurred. After a positive indication from the non-invasive methods, a small surgical incision was made to visually examine the gonads and to retrieve the DST tags from the abdominal cavity.

Both female pallid sturgeon were determined to have spawned completely.
The first female, captured on March 26, 2007, at river mile 659.7 with an egg polarization index of 0.17 , moved 109.1 river miles upstream before spawning upstream from Ponca State Park within the Missouri National Recreational River segment, probably in mid-May. It was recaptured after moving downstream to river mile 756.5 on May 23, 2007 (fig. 4). The second female was captured on March 29, 2007, at river mile 650.3 with an egg polarization index of 0.12 , and moved nearly 50 miles upstream from the implantation location before spawning in the channelized reach downstream from Sioux City, Iowa (river mile 734), probably in late April to early May. This fish was recaptured on May 25, 2007, at river mile 676.7 after moving downstream. Both fish were in good overall physical condition upon recovery.

This is the first direct evidence that pallid sturgeon spawn in the Missouri National Recreational River segment and in the channelized river upstream from the Platte River. The DST data, in combination with telemetry relocations, are the first complete records of pallid sturgeon that migrated and spawned. Analysis of depth data recorded by DST tags also indicates a characteristic pattern of behavior that may be associated with spawning. Whereas researchers successfully documented spawning, this study does not reveal whether or not spawning occurred under optimal conditions, or whether or not enough eggs hatched or young survived to add to the pallid sturgeon population. Although spawning occurred in 2007 without flow modification from Gavins Point Dam, fish may have responded to natural spring pulses from tributaries. Data from pallid sturgeon will be compared with observations on shovelnose sturgeon to assess spawning and characterize reproductive strategies of the two species.

\section{Additional Research Accomplishments}

In addition to the results summarized above, the 2007 research efforts have yielded additional accomplishments:

- Observations of movement and habitat use by pallid sturgeon and shovelnose sturgeon indicate that spawning occurs during an extended time at multiple locations within the study segments. Female reproductive movement seems to be characterized in both species by a significant and rapid upstream movement, followed by sporadic downstream movement. Movement patterns of reproductive male sturgeon appear to be more complex. Data indicate that some reproductive male pallid and shovelnose sturgeon show more diverse movement patterns during the spawning.

- Telemetry data document that reproductive and non-reproductive shovelnose sturgeon used the mainstem and some tributaries to the Missouri River before, during, and after spawning. In contrast, pallid sturgeon used only mainstem Missouri River habitat or areas near tributary confluences. None of the 5 tagged pallid sturgeon have been observed in Missouri River tributaries.

- Hydrologists mapped 10 highprobability spawning reaches as determined from fish tracking data. Maps include depth, velocity, and substrate distributions that will be analyzed to delineate physical factors that contribute to sturgeon reproduction. 
- Water-quality monitors at multiple USGS streamflow-gaging stations along the river recorded changes in temperature, $\mathrm{pH}$, turbidity, and dissolved oxygen as they varied with discharge. These water-quality changes will be analyzed to assess their roles as cues in spawning behavior.

- Research biologists with the USGS and the South Dakota Game, Fish, and Parks have been sampling the Missouri River area below Gavins Point Dam for eggs and larval sturgeon using fine meshed nets. Once these samples are analyzed, additional verification may be obtained that sturgeon spawned and eggs hatched in that area.

\section{For more information contact:}

Michael Mac, Director

U.S. Geological Survey

Columbia Environmental Research Center 4200 New Haven Road

Columbia, Missouri 65201

Phone: 573-876-1900

Email:mmac@usgs.gov
Gerald Mestl

Nebraska Game and Parks Commission 2200 North 33rd Street

Lincoln, Nebraska 68503

Phone: 402-471-1512

Email: gerald.mestl@ngpc.ne.gov 